\title{
Family-Based Next-Generation Sequencing Study Identifies an IL2RG Variant in an Infant with Primary Immunodeficiency
}

\author{
Aravind K. Bandari, ${ }^{1-3}$ Sunil Bhat, ${ }^{4}$ MV Archana, ${ }^{4}$ Sunita Yadavalli, ${ }^{1}$ Krishna Patel, ${ }^{1,5}$ \\ Pavithra Rajagopalan, ${ }^{1}$ Anil K. Madugundu, ${ }^{1-3,6,7}$ Manisha Madkaikar, ${ }^{8}$ Kavita Reddy, \\ Babylakshmi Muthusamy, ${ }^{1-3}$ and Akhilesh Pandey ${ }^{3,6,7}$
}

\begin{abstract}
Primary immunodeficiencies (PIDs) are a rare and heterogeneous group of inherited genetic disorders that are characterized by an absent or impaired immune system. In this report, we describe the use of next-generation sequencing to investigate a male infant with clinical and immunological manifestations suggestive of a PID. Whole-exome sequencing of the infant along with his parents revealed a novel nucleotide variant (cytosine to adenine substitution at nucleotide position 252) in the coding region of the interleukin 2 receptor subunit gamma $(I L 2 R G)$ gene. The mother was found to be a carrier. These findings are consistent with a diagnosis of $\mathrm{X}$-linked severe combined immunodeficiency and represent the first such reported mutation in an Indian family. This mutation leads to an asparagine to lysine substitution (p.Asn84Lys) located in the extracellular domain of IL2RG, which is predicted to be pathogenic. Our study demonstrates the power of next-generation sequencing in identifying potential causative mutations to enable accurate clinical diagnosis, prenatal screening, and carrier female detection in PID patients. We believe that this approach, which is not a current routine in clinical practice, will become a mainstream component of individualized medicine in the near future.
\end{abstract}

Keywords: molecular diagnostics, bone marrow transplantation, primary immunodeficiency, genetic defects, next-generation sequencing, newborn screening

\section{Introduction}

$\mathbf{P}$ RIMARY IMMUNODEFICIENCIES (PIDs) are a group of chronic genetic disorders in which a part of the immune system is missing or incompletely developed (Bousfiha et al., 2015). Delayed diagnosis of PID increases the risk of morbidity and mortality of the patients. The 2017 report of International Union of Immunological Societies (IUIS) has classified the known PIDs into nine major categories that include (1) immunodeficiencies affecting cellular and humoral immunity, (2) combined immunodeficiencies with associated or syndromic features, (3) predominantly antibody deficiencies, (4) diseases of immune dysregulation, (5) congenital defects of phagocyte number, function, or both, (6) defects in intrinsic and innate immunity, (7) autoinflammatory disorders, (8) deficiency of the complement system, and (9) phenocopies of PID (Bousfiha et al., 2018).

Among the PIDs, severe combined immunodeficiency (SCID) is a potentially fatal disorder characterized by markedly decreased or absent circulating $\mathrm{T}$ cells, normal/ increased or decreased/absent circulating B cells, and decreased serum antibodies (immunoglobulin [Ig]) (Cirillo et al., 2015; Lee et al., 2011; Picard et al., 2015). The incidence of SCID is estimated to be 1 in 100,000 (Lindegren

\footnotetext{
${ }^{1}$ Institute of Bioinformatics, Bangalore, India.

${ }^{2}$ Manipal Academy of Higher Education, Manipal, Karnataka, India.

${ }^{3}$ Center for Molecular Medicine, National Institute of Mental Health and Neurosciences (NIMHANS), Bangalore, India.

${ }_{5}^{4}$ Pediatric Hematology, Oncology and Bone Marrow Transplant, Mazumdar Shaw Medical Center, Narayana Health City, Bangalore, India.

${ }^{5}$ Amrita School of Biotechnology, Amrita Vishwa Vidyapeetham, Kollam, India.

${ }^{6}$ Department of Laboratory Medicine and Pathology, Mayo Clinic, Rochester, Minnesota.

${ }^{7}$ Center for Individualized Medicine, Mayo Clinic, Rochester, Minnesota.

${ }^{8}$ National Institute of Immunohaematology, KEM Hospital Campus, Mumbai, India.

(C) Aravind K. Bandari, et al., 2019. Published by Mary Ann Liebert, Inc. This Open Access article is distributed under the terms of the Creative Commons License (http://creativecommons.org/licenses/by/4.0), which permits unrestricted use, distribution, and reproduction in
} any medium, provided the original work is properly credited. 
Table 1. Flow Cytometry Findings in the Proband

\begin{tabular}{|c|c|c|c|}
\hline Cell type & $\begin{array}{c}\text { Lymphocyte } \\
\text { count }(\%)\end{array}$ & $\begin{array}{c}\text { Absolute } \\
\text { lymphocyte } \\
\text { count } \\
(\text { cells } / \mu L)\end{array}$ & $\begin{array}{c}\text { Reference } \\
\text { range for } \\
\text { absolute } \\
\text { count } \\
(\text { cells } / \mu L)\end{array}$ \\
\hline Lymphocytes & 1.7 & 100 & $700-4500$ \\
\hline $\mathrm{CD}^{+}$( $\mathrm{T}$ cells $)$ & 16.1 & 16 & $542-2327$ \\
\hline $\mathrm{CD} 9^{+}$(B cells $)$ & 76.6 & 77 & $61-509$ \\
\hline $\begin{array}{r}\mathrm{CD}^{-} \mathrm{CD}^{-} 6^{+} \\
\text {(NK cells) }\end{array}$ & 0.7 & 1 & $28-418$ \\
\hline $\begin{array}{l}\mathrm{CD}^{+} \mathrm{CD}^{+} \\
\quad\left(\mathrm{CD} 4^{+} \text {cells }\right)\end{array}$ & 11.9 & 12 & $350-1600$ \\
\hline $\begin{array}{l}\mathrm{CD}^{+} \mathrm{CD}^{+} \\
\quad\left(\mathrm{CD}^{+} \text {cells }\right)\end{array}$ & 2.6 & 3 & $300-1450$ \\
\hline $\mathrm{CD}^{2} 0^{+}$(B cells $)$ & 91.2 & 91 & $66-529$ \\
\hline
\end{tabular}

NK, natural killer.

et al., 2004) newborns in the world and 1 in 58,000 in the U.S. population (Kwan et al., 2014). Patients with SCID are generally asymptomatic at birth but later present with persistent infections, especially with opportunistic pathogens, including Acinetobacter, Pseudomonas, Aspergillus, Candi- $d a$, cytomegalovirus, and herpes zoster virus (Fischer et al., 2015). Affected infants develop these infections during their first few months of age and generally die before 1 year of their age, if untreated.

Mutations in 17 genes are currently known to cause SCID, which are involved in the $\mathrm{T}$ lymphocyte differentiation process. Among those genes, IL2RG, JAK3,IL7R, PTPRC, $C D 3 D, C D 3 E, C D 247, C O R O 1 A$, and $L A T$ are reported to cause T-B+ SCID and RAG1, RAG2, DCLRE1C, PRKDC, NHEJ1, LIG4, AK2, and ADA are known to cause T-B-SCID (Picard et al., 2018). These genes are associated with an autosomal recessive mode of inheritance except for interleukin 2 receptor subunit gamma (IL2RG), which is the only causative gene located on the $\mathrm{X}$-chromosome and thus associated with an X-linked recessive mode of inheritance. IL2RG mutations are estimated to account for $40-50 \%$ of the SCID patients (Chan and Puck, 2005; Kalman et al., 2004; Touzot et al., 2015).

$I L 2 R G$ gene codes for the common gamma chain that acts as a signal transducing subunit for several interleukin receptors, including IL-2, IL-4, IL-7, IL-9, IL-15, and IL-21. It is therefore crucial for the development and function of both the innate and adaptive immune systems (Asao et al., 2001; Conley et al., 1999; Rochman et al., 2009). The IL2RG

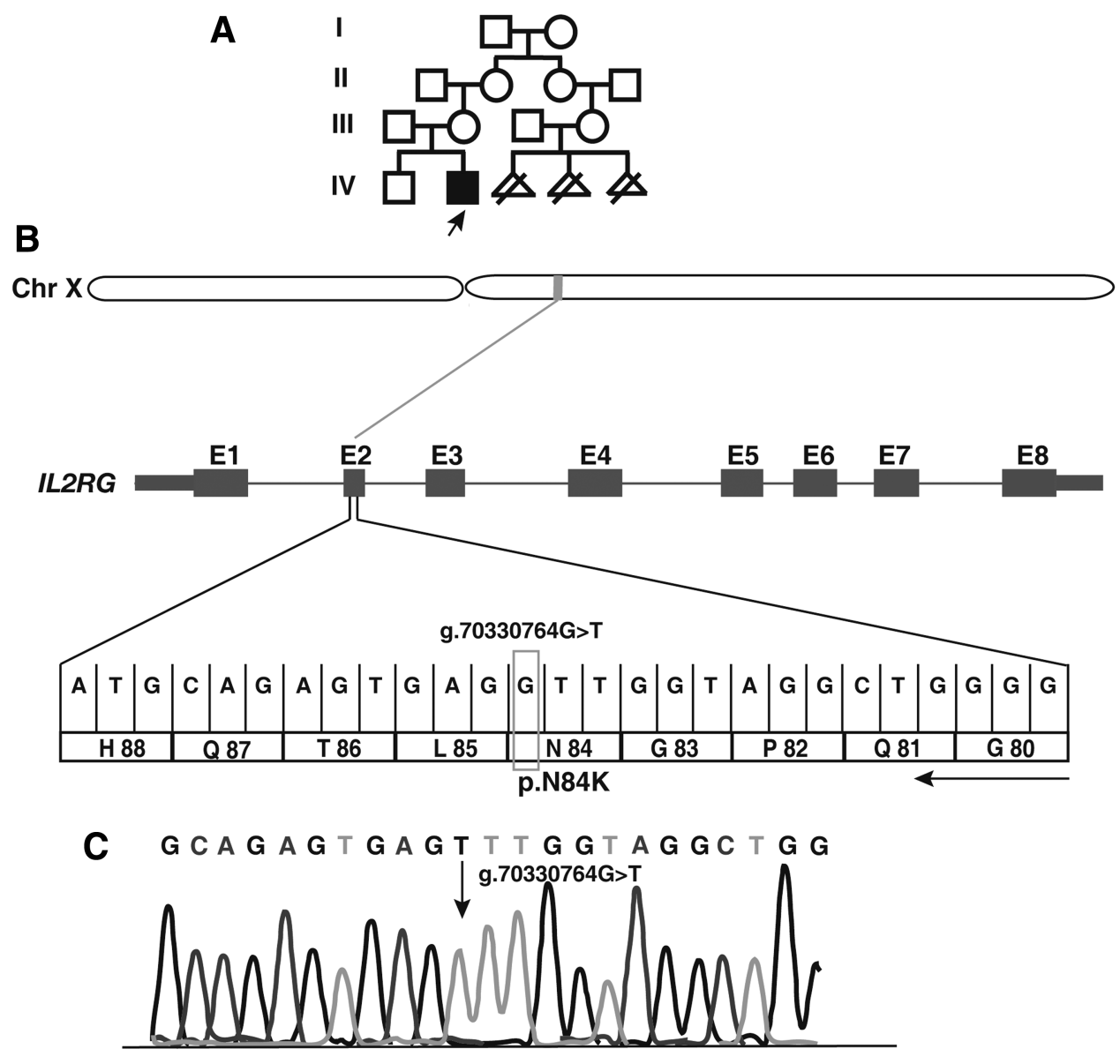

FIG. 1. A novel mutation identified in an infant with X-linked SCID. (A) The family pedigree is shown where the arrow indicates the proband who was sequenced along with his parents. (B) Depiction of single-nucleotide variant g.70330764G $>$ T identified in exon 2 of $I L 2 R G$ gene located on the X-chromosome. The exons of $I L 2 R G$ are shown as rectangular boxes labeled E1 through E8. (C) A chromatogram from Sanger sequencing-based validation of g. $70330764 \mathrm{G}>\mathrm{T}$ variant in the $I L 2 R G$ gene in the patient. The mutation is indicated by the arrow. IL2RG, interleukin 2 receptor subunit gamma; SCID, severe combined immunodeficiency. 
protein has a signal peptide (1-22), an extracellular domain with Ig repeats (23-262), a transmembrane domain (263-283), and a short cytoplasmic tail (284-369) (Bai et al., 2015). IL2RG is predicted to contain six potential N-linked glycosylation sites at positions 24, 71, 75, 84, 159, and 249 (UniProt ID: P31785).

The common gamma chain is crucial for IL-2 signaling as it forms an oligomeric complex with IL-2 receptor-alpha and -beta subunits in response to IL-2 stimulation and activates Janus kinases (JAK1 and JAK3), which lead to downstream activation of signal transducer and activator of transcription 5 (STAT5) (Picard et al., 2015), phosphoinositide 3-kinase signaling (PI3K), and mitogen-activated protein kinase (MAPK) pathways (Nakarai et al., 1994; Picard et al., 2015; Waickman et al., 2016).

Owing to the heterogeneous clinical presentation and high mortality rates, rapid diagnosis is important to initiate treatment regimens such as hematopoietic stem cell transplantation and enzyme replacement therapy that can significantly improve the survival of children with SCID (Ferrua and Aiuti, 2017; Kohn and Gaspar, 2017). Here, we report the clinical and immunological manifestations of a male infant who presented with repeated infections. Whole-exome sequencing of the infant and his parents revealed a novel nucleotide variant c. $252 \mathrm{C}>\mathrm{A}$ in the $I L 2 R G$ gene that resulted in an amino acid change of asparagine to lysine (p.Asn84Lys) as a potential cause for the SCID. Our study highlights the importance of next-generation sequencing approach as a means to identify potential causal variants in clinically and genetically heterogeneous diseases such as SCID.

\section{Materials and Methods}

\section{Ethics statement}

This study was approved by the institutional ethics committee (Narayana Health Academic Ethics Committee).

\section{Patient history}

A male infant born to nonconsanguineous parents from the southern part of India was enrolled in this study. The patient was normal at birth, but at 6 months of age presented with an eczematous rash and a history of repeated infections. Initially, he was treated for seborrheic dermatitis; however, the rash was later determined to be due to low lymphocyte counts. He was readmitted at the age of 11 months with convulsions and altered sensorium. Except for respiratory failure, no other organ failure was observed. The blood profile showed low hemoglobin $9.5 \mathrm{~g} / \mathrm{dL}$ (normal range: 11.1-14.1) and low mean corpuscular hemoglobin $21.8 \mathrm{pg}$ (normal range: 24.0-30.0). Platelet, neutrophil, and monocyte counts were also low.

Flow cytometry tests revealed normal B cell counts with decreased $\mathrm{T}$ and natural killer (NK) cell counts and low levels of serum Igs (Table 1), a pattern consistent with SCID cases (Picard et al., 2015). The proband was awaiting a human leukocyte antigen-matched donor for bone marrow transplantation when he expired on developing pneumonia and sepsis at the age of 11 months. His elder brother was a healthy 3-year old and there was no history of SCID in the family. The mother's cousin had three miscarriages in early pregnancies due to unknown reasons (Fig. 1A).

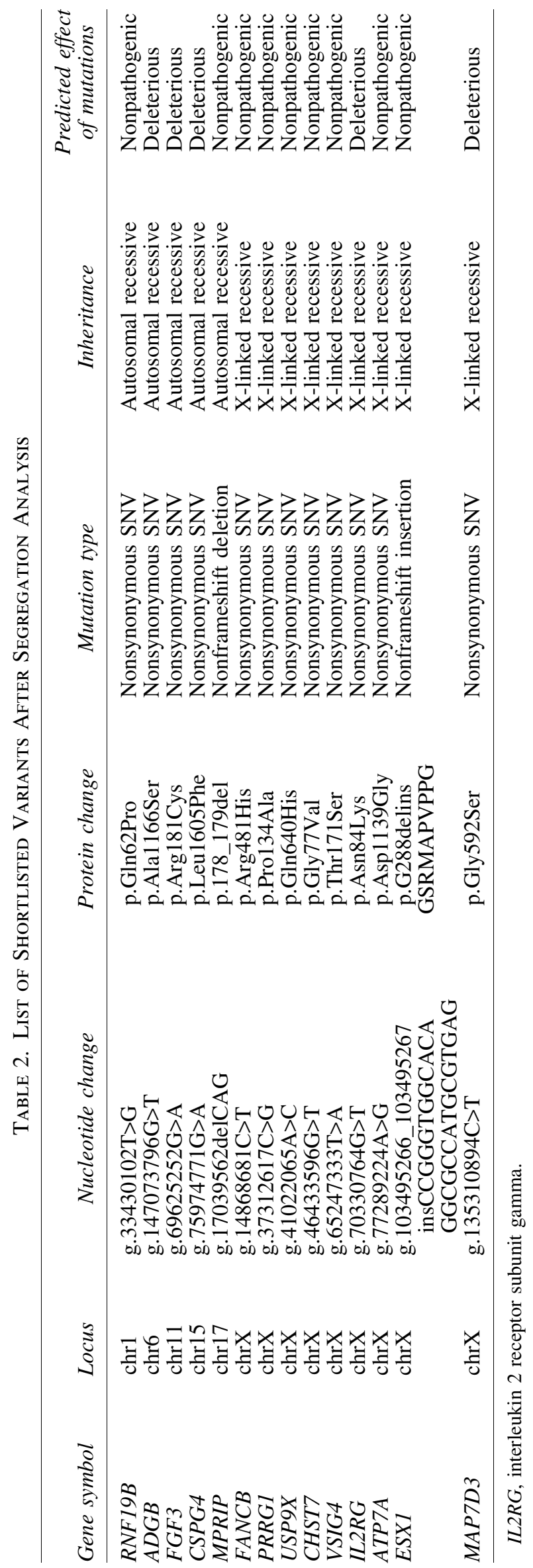




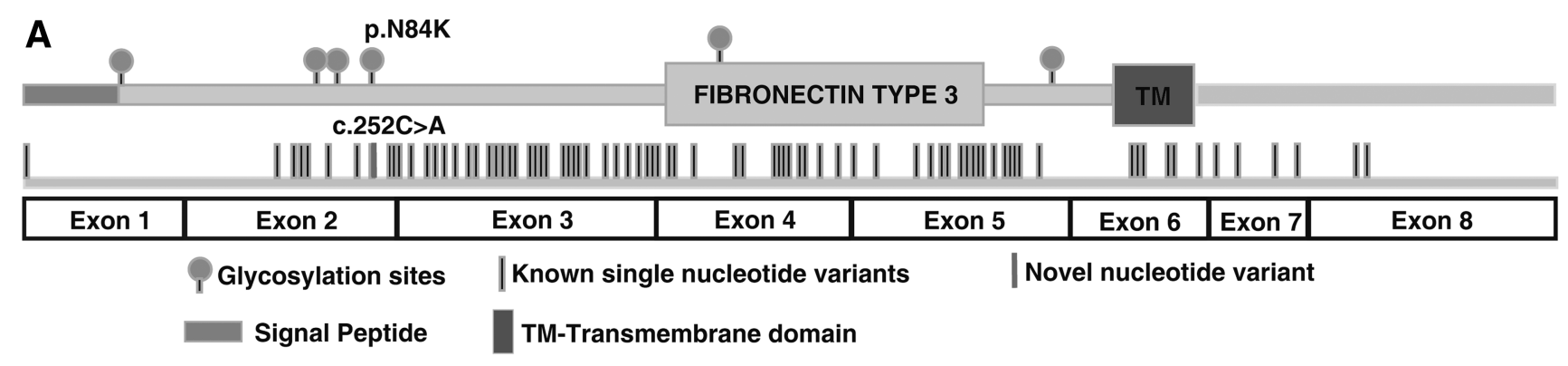

B

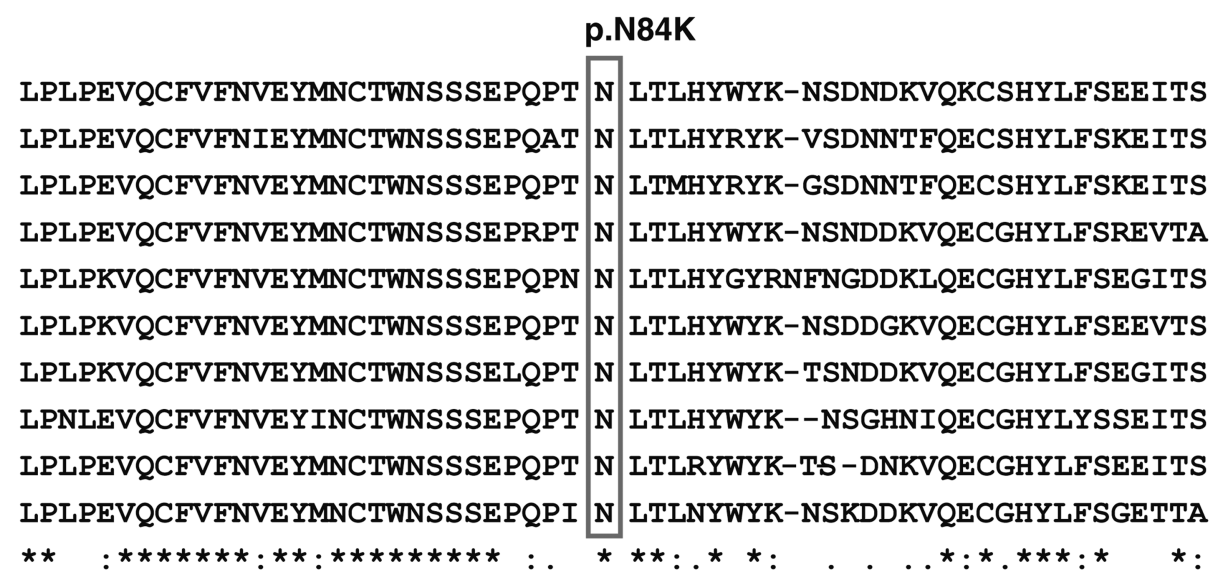

FIG. 2. Depiction of $I L 2 R G$ gene mutation in the context of protein architecture and sequence conservation. (A) A schematic representation of the IL2RG protein. The top part shows the domain architecture that includes signal peptide (red), fibronectin type 3 domain, and transmembrane domain (TM). The location of glycosylation sites is also indicated (ball and stick representation). The middle part shows the novel missense mutation identified in this study along with previously reported missense mutations. The lower part shows the spliced exonic architecture of the IL2RG gene. (B) Depiction of conservation of the asparagine residue, which was found to be mutated to lysine in the affected infant, across species. The conserved asparagine is indicated by a rectangular box.

\section{Laboratory assessment of the patient}

The patient was ascertained by trained immunologists and geneticists. Whole blood was collected from the patient and his parents after procuring informed consent from the family. Intact white blood cells were obtained from whole blood after lysis of red blood cells (RBC) with RBC lysis buffer. Leukocytes were stained with fluorochrome-conjugated antihuman cell surface markers. Cell events were captured using fluorescence-activated cell scan, and low subsets of T cells (CD3, CD4, CD8), NK cells (CD56), and low levels of serum Igs (IgG, IgA, IgM, IgE, and IgD) were observed. The number of B cells CD19 (+) in the patient was similar to normal controls. The cell surface markers were measured using a flow cytometer and clinical, laboratory findings confirmed SCID in the patient (Table 1).

\section{Exome sequencing and bioinformatic analysis}

Blood samples were collected from the patient and his parents. Genomic DNA was extracted from whole blood using the QIAamp DNA Blood Mini Kit (Catalog number 51104; Qiagen). Three micrograms of genomic DNA was used for sequencing and the DNA library for exome sequencing was prepared using the Agilent Technologies SureSelect ${ }^{\mathrm{XT}}$ Human All Exon V5 kit. Paired-end sequencing was performed on the Illumina HiSeq 2500 (Illumina) with read length of $100 \mathrm{bp}$ for the whole exome using the TruSeq Cluster Kit v3 (Catalog number PE-401-3001; Illumina, Inc.), following the manufacturer's protocols.
The analysis of sequencing data, variant calling, and variant filtering were carried out as described previously ( $\mathrm{Mu}-$ thusamy et al., 2017). Sanger sequencing was performed to validate the $I L 2 R G$ variant in the patient using the forward primer (5'-GGCTGCACTTCTGGACTTTA-3') and reverse primer (5'-CTAGATTTCTTCCTGACCAC-3').

\section{Results and Discussion}

Whole-exome sequencing of the patient and both of his parents resulted in an average of 96 million paired-end reads. Approximately, 96\% reads were high quality $(q \geq 20)$ and aligned to the reference genome (hg19). A mean depth of $95 \times$ was obtained across the three samples. The genotyped variants of the patient, mother, and father were subjected to joint variant calling using Genome Analysis Toolkit. We obtained 108,482 variants, of which 17,688 variants were located in the $\mathrm{X}$-chromosome. We used ANNOVAR to annotate the variants and identified 60,354 exonic, 272 splice sites, and 519,518 intronic variants across samples. Furthermore, common variants with minor allele frequency $>0.01$ were removed after comparing the variants with common variants' databases such as 1000 Genome Project (Abecasis et al., 2012), NHLBI-EVS Exome Sequencing Project (http://evs.gs.washington.edu/ EVS), and ExAC database (Lek et al., 2016).

Filtering of all synonymous variants resulted in 1341 variants, of which 1302 were exonic and 39 were splice-site variants. Based on the pedigree and symptoms exhibited by 
Table 3. Prediction of Functional Effect of P.Asn84Lys Mutation in Interleukin 2 Receptor Subunit Gamma

\begin{tabular}{lcccccccc} 
Gene symbol & Accession & $\begin{array}{c}\text { Nucleotide } \\
\text { change }\end{array}$ & $\begin{array}{c}\text { Amino acid } \\
\text { change }\end{array}$ & SIFT & PolyPhen-2 & MutationTaster & $\begin{array}{c}\text { Common variants: } \\
\text { Minor allele } \\
\text { frequency }\end{array}$ \\
\hline$I L 2 R G$ & NM_000206 & c.252C $>\mathrm{A}$ & p.Asn84Lys & Deleterious & Damaging & Disease causing & 0 \\
\hline
\end{tabular}

SIFT, Sorts Intolerant From Tolerant.

the proband, we investigated $\mathrm{X}$-linked recessive as well as the autosomal recessive modes of inheritance. We obtained nine $\mathrm{X}$-linked recessive and three autosomal recessive variants (Table 2). These variants were further shortlisted based on the known immunologic functions of the genes.

We noted a potential causal variant, g.70330764G $>\mathrm{T}$, in exon 2 of the IL2RG gene located at Xq13.1 (Fig. 1B). This mutation replaces cytosine with adenine at position 252 (RefSeq Accession: NM_000206.2), resulting in an amino acid substitution of asparagine (neutral, hydrophilic) to lysine (positive, hydrophilic) at position 84 (p.Asn84Lys). The variant was hemizygous in the affected individual, heterozygous in the mother, and was not found in the father, confirming X-linked recessive mode of inheritance. Sanger sequencing confirmed the nucleotide substitution (Fig. 1C). The missense variant p.Asn84Lys is found at a predicted glycosylation site (UniProt ID: P31785) located in the conserved extracellular domain (23-262) (Fig. 2A).

A multiple sequence alignment of the IL2RG protein with other species showed conservation of the asparagine residue, which was mutated in the patient (Fig. 2B). SIFT (Sorts Intolerant From Tolerant), PolyPhen-2, and MutationTaster concurred in their prediction the effect of the mutation as potentially pathogenic (Table 3 ). This variant was not found in the common variant databases, including dbSNP, 1000 Genomes Project, ExAC, or EVS. Together, these results indicate that the mutation has occurred in a potentially functional amino acid and may lead to a deleterious effect on the protein function.

In summary, we identified a novel nucleotide variant c.252C>A (NM_000206.2), which results in a codon change from AAC to AAA leading to an amino acid substitution of asparagine to lysine (p.Asn84Lys). Fugmann et al. (1998) used nonradioactive single-strand confirmation polymorphism followed by sequencing and found a different nucleotide change (c.266C>G; NM_000206.1), corresponding to a codon change from AAC to AAG resulting in the same amino acid substitution that we have observed. Thus, our report describes a novel nucleotide variant in the $I L 2 R G$ gene. Knowledge of this novel mutation is relevant for future targeted diagnostics that might employ the use of specific primers to amplify known nucleotide variants using polymerase chain reaction (PCR)-based techniques.

This report is also the first familial study showing the segregation of this mutation in the patient and his parents. This study reports the first mutation in $I L 2 R G$ gene in an SCID patient from an Indian family. Because this is a rare disorder, it is important to note that our study serves also as a validation for the previous study that described p.Asn84Lys as a change in an SCID patient, indicating the causative nature of this mutation in SCID. Our study confirms that this mutation can be considered a causative mutation for SCID and used in clinical diagnosis of this condition as well for genetic counseling as the basis for initiating therapy.

\section{Conclusions}

PID diseases are clinically and genetically heterogeneous for which accurate diagnosis is essential for improving therapeutic outcomes. SCID is potentially fatal, with mutations in IL2RG gene being the most common cause. Next-generation sequencing-based clinical diagnosis can greatly increase the diagnostic yield because multiple genes are simultaneously tested.

In this study, we applied next-generation sequencing on the patient and his parents and identified a novel nucleotide change (c.252C $>\mathrm{A})$ that resulted in an amino acid change of asparagine to lysine at position 84 . This amino acid substitution in the extracellular domain likely leads to an abnormal or unstable common gamma chain, thereby affecting signaling downstream of several interleukins (Conley et al., 1999). This novel variant can now be included in targeted sequencing-based assays in the setting of PIDs. Our report expands our understanding of currently known mutations in PID and underscores the power of next-generation sequencing as a potential diagnostic tool for PIDs.

\section{Acknowledgments}

We thank the family for providing us samples for this study. This work was supported by the Wellcome Trust/DBT India Alliance Margdarshi Fellowship [grant number IA/M/ 15/1/502023] awarded to Akhilesh Pandey. We thank the "Infosys Foundation" for research support to the Institute of Bioinformatics. Babylakshmi Muthusamy is a recipient of the DBT-BioCARe Women Scientist Award from the Department of Biotechnology, Government of India. Aravind K. Bandari and Pavithra Rajagopalan are recipients of the Senior Research Fellowship from the Council of Scientific and Industrial Research (CSIR), Government of India.

\section{Author Disclosure Statement}

The authors declare there are no competing financial interests.

\section{References}

Abecasis GR, Auton A, Brooks LD, et al. (2012). An integrated map of genetic variation from 1,092 human genomes. Nature 491, 56-65.

Asao H, Okuyama C, Kumaki S, et al. (2001). Cutting edge: The common gamma-chain is an indispensable subunit of the IL-21 receptor complex. J Immunol 167, 1-5.

Bai QL, Liu N, Kong XD, Xu XJ, and Zhao ZH. (2015). Mutation analyses and prenatal diagnosis in families of $\mathrm{X}$-linked severe combined immunodeficiency caused by IL2Rgamma gene novel mutation. Genet Mol Res 14, 6164-6172. 
Bousfiha A, Jeddane L, Al-Herz W, et al. (2015). The 2015 IUIS phenotypic classification for primary immunodeficiencies. $\mathrm{J}$ Clin Immunol 35, 727-738.

Bousfiha A, Jeddane L, Picard C, et al. (2018). The 2017 IUIS phenotypic classification for primary immunodeficiencies. $\mathrm{J}$ Clin Immunol 38, 129-143.

Chan K, and Puck JM. (2005). Development of populationbased newborn screening for severe combined immunodeficiency. J Allergy Clin Immunol 115, 391-398.

Cirillo E, Giardino G, Gallo V, et al. (2015). Severe combined immunodeficiency-An update. Ann N Y Acad Sci 1356, 90-106.

Conley ME, Notarangelo LD, and Etzioni A. (1999). Diagnostic criteria for primary immunodeficiencies. Representing PAGID (Pan-American Group for Immunodeficiency) and ESID (European Society for Immunodeficiencies). Clin Immunol 93, 190-197.

Ferrua F, and Aiuti A. (2017). Twenty-five years of gene therapy for ADA-SCID: From bubble babies to an approved drug. Hum Gene Ther 28, 972-981.

Fischer A, Notarangelo LD, Neven B, Cavazzana M, and Puck JM. (2015). Severe combined immunodeficiencies and related disorders. Nat Rev Dis Primers 1, 15061.

Fugmann SD, Muller S, Friedrich W, Bartram CR, and Schwarz K. (1998). Mutations in the gene for the common gamma chain (gammac) in X-linked severe combined immunodeficiency. Hum Genet 103, 730-731.

Kalman L, Lindegren ML, Kobrynski L, et al. (2004). Mutations in genes required for T-cell development: IL7R, CD45, IL2RG, JAK3, RAG1, RAG2, ARTEMIS, and ADA and severe combined immunodeficiency: HuGE review. Genet Med 6, 16-26.

Kohn DB, and Gaspar HB. (2017). How we manage adenosine deaminase-deficient severe combined immune deficiency (ADA SCID). J Clin Immunol 37, 351-356.

Kwan A, Abraham RS, Currier R, et al. (2014). Newborn screening for severe combined immunodeficiency in 11 screening programs in the United States. JAMA 312, 729-738.

Lee PP, Chan KW, Chen TX, et al. (2011). Molecular diagnosis of severe combined immunodeficiency-Identification of IL2RG, JAK3, IL7R, DCLRE1C, RAG1, and RAG2 mutations in a cohort of Chinese and Southeast Asian children. J Clin Immunol 31, 281-296.

Lek M, Karczewski KJ, Minikel EV, et al. (2016). Analysis of protein-coding genetic variation in 60,706 humans. Nature 536, 285-291.

Lindegren ML, Kobrynski L, Rasmussen SA, et al. (2004). Applying public health strategies to primary immunodeficiency diseases: A potential approach to genetic disorders. MMWR Recomm Rep 53, 1-29.

Muthusamy B, Selvan LDN, Nguyen TT, et al. (2017). Nextgeneration sequencing reveals novel mutations in X-linked intellectual disability. OMICS 21, 295-303.

Nakarai T, Robertson MJ, Streuli M, et al. (1994). Interleukin 2 receptor gamma chain expression on resting and activated lymphoid cells. J Exp Med 180, 241-251.

Picard C, Al-Herz W, Bousfiha A, et al. (2015). Primary immunodeficiency diseases: An update on the classification from the international union of immunological societies expert committee for primary immunodeficiency 2015. J Clin Immunol 35, 696-726.

Picard C, Bobby Gaspar H, Al-Herz W, et al. (2018). International union of immunological societies: 2017 primary immunodeficiency diseases committee report on inborn errors of immunity. J Clin Immunol 38, 96-128.

Rochman Y, Spolski R, and Leonard WJ. (2009). New insights into the regulation of $\mathrm{T}$ cells by gamma(c) family cytokines. Nat Rev Immunol 9, 480-490.
Touzot F, Moshous D, Creidy R, et al. (2015). Faster T-cell development following gene therapy compared with haploidentical HSCT in the treatment of SCID-X1. Blood 125, 3563-3569.

Waickman AT, Park JY, and Park JH. (2016). The common gamma-chain cytokine receptor: Tricks-and-treats for T cells. Cell Mol Life Sci 73, 253-269.

Address correspondence to: Akhilesh Pandey, MD, PhD

Department of Laboratory Medicine and Pathology Mayo Clinic

Rochester, MN 55905

E-mail: pandey.akhilesh@mayo.edu

Babylakshmi Muthusamy, PhD Institute of Bioinformatics

Discoverer Building, 7th Floor

International Technology Park

Whitefield Road

Bangalore 560066

India

E-mail: babylakshmi@ibioinformatics.org

Sunil Bhat, MD, FPHO, FRAH

Pediatric Hematology, Oncology

and Bone Marrow Transplant

Mazumdar Shaw Medical Centre

Narayana Health City

Bangalore 560099

India

E-mail: sunil.bhat.dr@narayanahealth.org

\begin{tabular}{|c|}
\hline $\begin{aligned} & \text { Abbreviations Used } \\
& \text { ADA }=\text { adenine deaminase } \\
& \text { AK2 }=\text { adenylate kinase } 2 \\
& \text { CORO1A }=\text { coronin 1A } \\
& \text { DCLRE1C }=\text { DNA crosslink repair } 1 \mathrm{C} \\
& \text { IgA }=\text { immunoglobulin A } \\
& \text { IgD }=\text { immunoglobulin } \mathrm{D} \\
& \text { IgE }=\text { immunoglobulin E } \\
& \text { IgG }=\text { immunoglobulin } \mathrm{G} \\
& \text { IgM }=\text { immunoglobulin } \mathrm{M} \\
& \text { IL2RG }=\text { interleukin } 2, \text { receptor gamma } \\
& \text { IUIS }=\text { International Union of } \\
& \text { Immunological Societies } \\
& \text { JAK1 }=\text { Janus kinase } 1 \\
& \text { JAK3 }=\text { Janus kinase } 3 \\
& \text { LIG4 }=\text { DNA ligase } 4 \\
& \text { MAPK }=\text { mitogen-activated protein kinase } \\
& \text { NK }=\text { natural killer } \\
& \text { PI3K }=\text { phosphoinositide } 3 \text {-kinase } \\
& \text { PIDs }=\text { primary immunodeficiencies } \\
& \text { PRKDC }=\text { protein kinase }, \text { DNA-activated }, \text { catalytic } \\
& \text { PTPRC }=\text { polypeptide } \\
& \text { RAG1 }=\text { recombination activating } 1 \\
& \text { RAG2 }=\text { recombination activating } 2 \\
& \text { RBC }=\text { red blood cells } \\
& \text { SCID }=\text { severe combined immunodeficiency } \\
& \text { SIFT }=\text { sorts intolerant from tolerant } \\
& \text { STAT5 }=\text { signal transducer and activator of } \\
& \text { transcription } 5\end{aligned}$ \\
\hline
\end{tabular}

